\title{
Strategic Hedging: A Comparative Study of Methods, Results and Discussion (and Conclusion) Sections of Research Articles in English and Russian
}

\author{
Elena Zanina \\ National Research University Higher School of Economics \\ Correspondence concerning this article should be addressed to Elena Zanina, Department of English \\ Language for Social Sciences, the National Research University Higher School of Economics, 33/5 \\ Kirpichnaya Ulitsa, Moscow, Russia, 105187.E-mail: ezanina@yandex.ru
}

\begin{abstract}
A great deal of research has established the importance of hedging and its cross-linguistic differences for intercultural academic communication and, consequently, for L2 EAP/ESP teaching and learning. However, strategic hedging seen as discourse-based hedging strategies related to the rhetorical structure of research papers seems to be underexplored. The article reports on a mainly descriptive study of its cross-linguistic variation in the Methods, Results and Discussion (and Conclusion) sections of English-medium and Russian-medium research articles in the field of management and marketing. Based on D. Koutsantoni's taxonomy, this paper analyzes 20 published articles to compare the types, frequencies and reveal some tendencies of using strategic hedges in both languages. The research detects the same two major categories of strategic hedges (agreement with other research and limitations) for both languages, with the same further subcategorization for each of them. The findings reveal differences between the languages in the overall frequencies of strategic hedges and the frequencies of their subtypes, as well as in tendencies of their usage including Russian writers' preference for referring to general opinion, implicit ways of expressing limitations and giving one explanation for obscure results, as compared to English writers. The research outcomes indicate that cross-linguistic variation of strategic hedging in English-medium and Russian-medium research articles is an important feature to be taken into account in EAP/ESP teaching and learning.
\end{abstract}

Keywords: hedging, strategic hedging, academic research article, methods, results and discussion/ conclusion sections, cross-linguistic

Since the introduction of the term 'hedging' by Lakoff (1972), the hedging phenomenon has been the subject of a considerable body of studies within various linguistic research frameworks (logical and semantic, discourse-oriented, cognitive, pragmatic, and other). Within the pragmatic approach which emerged in the 1980s and has developed into the leading framework for linguistic study of hedging, this phenomenon is viewed as a strategy that 'attenuates either the full semantic value of a particular expression...or the full force of a speech act' (Fraser, 2010, p. 15). Appropriate use and adequate perception of hedging is considered indispensable to achieving pragmatic competence defined as 'the ability to communicate your intended message with all its nuances in any socio-cultural context and to interpret the message of your interlocutor as it was intended' (Fraser, 2010, p. 15).

Recent decades have seen an upsurge of interest to hedging in academic discourse, which reveals the critical role of hedging in this type of discourse (Hyland, 2004a, p.6) where the necessity to present new knowledge with both precision and caution is essential. Consequently, a substantial amount of research into hedging in ESP/ EAP contexts has appeared (Hyland, 2004b; Hyland \& Tse, 2004; Hinkel, 2005; Lewin, 2005), pinpointing the clear importance of hedging for developing pragmatic competence in ESP/EAP areas. It is acknowledged that if non-native speakers (NNSs) do not use hedging, or use it inappropriately, they break the communication rules accepted in the target language, therefore their 
message can be misapprehended, or they can be seen as impolite, inappropriate or insulting. If NNSs fail to interpret the hedged utterance correctly, they may misconceive it (Fraser, 2010). Both cases are seen as potential sources of communicative error which can impede communication or even cause communication failure.

As important as hedging is in academic discourse, and, consequently, in ESP/EAP teaching and learning, it is mainly lexical and syntactic hedging devices that have been scrutinized in linguistic and pedagogical research. However, little is known about strategic markers of hedging (Hyland, 2004a) in which the mitigation effect does not stem from the use of specific language units, but is rather related to discoursebased strategies referring to an imperfect model, methods, lack of knowledge, and other drawbacks of the research. Moreover, though hedging research definitely has important implications for ESL teaching and learning, specifically, in ESP/EAP areas, even less is known about cross-linguistic differences in realizing strategic hedging in specific domains of science.

This paper attempts to partially bridge this gap by focusing on contrastive investigation of strategic hedges in the Methods, Results and Discussion sections of articles following the IMRD (Introduction - Methods - Results - /and Discussion) rhetorical model, and Conclusion sections for articles following the IMRDC (Introduction - Methods - Results -/and Discussion Conclusion) model of academic research articles (RAs) on management and marketing written in English and Russian. The research aims to determine if there are any cross-linguistic differences in this respect, and if they are detected, to provide a comparative overview of strategic hedges used in each of the languages in RAs in this field in terms of their frequency and preferences in usage. The research is basically descriptive and does not aim at making a thorough quantitative analysis. Rather, it intends to detect and compare the main tendencies in the use of strategic hedges in the field mentioned for both languages.

In this paper, first a brief overview of the evolution of this linguistic concept will be given and the functions of hedging in academic discourse will be mentioned, then the taxonomy of strategic hedging to be used in this research and the types of strategic hedges used in each language will be determined, the frequency of each type of strategic hedges in English-language and Russian-language articles will be calculated, and the differences will be briefly discussed.

\section{Materials and Methods}

\section{The Concept of Hedging}

Anticipated by Zadeh (1965 as cited in Fraser,
2010, p. 16) in his fuzzy set theory and by Weinreich in the concept of 'metalinguistic operators'(Weinreich, 1966 as cited in Fraser, 2010, p. 16), the concept of hedging was first introduced by Lakoff (1972). He approached hedging from the logical-semantic perspective defining hedges as 'words whose job is to make things fuzzier or less fuzzy' (Lakoff, 1972, p. 195). In discourse-oriented research, hedges are often viewed as discourse markers either affecting the truth-conditions of propositions, or demonstrating the degree of speaker's commitment to the truth-value of the proposition. In pragmatics, hedging is considered to be an interactional / communicative strategy of softening the speech act with the aim of avoiding potential communicative conflicts and is linked up to the notions of politeness (Brown \& Levinson,1987; Fraser, 2010) and vagueness (Fraser, 2010, among others). From an array of interpretations of hedging in various research frameworks relating it to fuzziness of notions, different pragmatic features and social functions of the discourse, the most widely recognized is probably the one which describes hedging as a way of expressing tentativeness and possibility to display 'either (a) a complete commitment to the truth value of an accompanying proposition, or (b) a desire not to express that commitment categorically' (Hyland, 2004a, p. 1).

\section{Hedging in Academic Discourse}

The plethora of research into hedging in academic discourse, its functions and frequency in various genres and rhetorical parts of academic research papers (Gillaerts \& Van de Velde, 2010; Koutsantoni, 2006, among others), across various disciplines (Fløttum et al., 2006; Vartalla, 2001; Vold, 2006), and different cultures/languages (Fløttum, Dahl, \& Kinn, 2006; Peterlin, 2005; Salager-Meyer, Ariza, \& Zambrano, 2003; Vassileva, 2001; Vold, 2006) has led to elaborating the concept of hedging, determining its functions, and various types of markers in academic context. Researchers assign several reasons for the frequent use of hedging in academic discourse: first, 'academics are crucially concerned with varieties of cognition, and cognition is inevitably hedged, with writers offering an assessment of the referential information they provide' (Hyland, 2004a, p. 6) to introduce new knowledge with the highest precision possible. Second, academic writers use hedges to 'present unproven claims with caution' (Hyland, 2004a, p. 6) to minimize potential damage to their image in case they claims are not accepted by the academic community. They do so in situations in which they feel their research is vulnerable due to drawbacks in methodology (too small samples, dubious justification of the research methods, questionable proofs and measurement techniques), ambiguity in interpreting the results, 
incompleteness of the research scope. Moreover, academic communication implies collaborating and negotiation between the writer and the reader in solving a problem, and since categorical assertions may contradict the readers' views and leave no way for a dialogue, the authors strive to reduce this potential threat by using hedged statements. Finally, hedging is a 'part of the academic discourse conventions; therefore, it is 'a substantial means by which scientists confirm their membership of the scientific community' (Hyland, 2004a, p. 6), thus creating credibility of their research.

\section{Research Article Structure and Strategic Hedges}

Academic research articles (RAs) are viewed as the core genre of written academic discourse due to their leading role in scientific knowledge dissemination and building researchers' reputation. In John Swales' most influential conception, genre is defined as 'a class of communicative events, the members of which share some set of communicative purposes' (Swales, 1990, p. 58) and is characterized by distinct rhetorical structure. In much of the ESP/EAP research the rhetorical structure of RAs is seen as comprising moves - 'bounded communicative acts' designed 'to achieve one main communicative objective' (Swales \& Feak, 2000, p. 35) - which can be further subdivided into steps.

Though for a long time hedging was supposed to be expressed mainly by lexical and syntactic means, there are some studies which mention, in addition to these, strategic hedges related to the rhetorical structure of an academic paper, i.e. to rhetorical moves and steps (Hyland, 2004a; Koutsantoni, 2006; Laane, 2010).

Hyland (2004a, p. 103) mentions among strategic hedges reference to limiting experimental conditions, reference to shortcomings in the model, theory or methodology and admission to a lack of knowledge. Koutsantoni (2006) provides a more precise categorization by distinguishing between five types of strategic hedging. In 'limitations of method' authors refer to imperfections in the research sample, framework or method to reduce the certainty of their research results, seeking to protect themselves from potential criticism by the discourse community. 'Limitations of scope' emphasize what authors prefer to discuss and what is beyond the scope of the study. 'Limitations of the study' pertain to the validity of the research, admitting the necessity of conducting additional research to confirm the results. Statements of 'agreement with other research' are also regarded as cautious ways for confirmation of one's claims, and are therefore included into strategic hedges. In 'limitations of knowledge' authors concede that they are unable to offer explanations for phenomena, provide comprehensive definitions and perfect models
(Koutsantoni, 2006). As stated by Hyland (2004a, p. 142), in doing so authors 'fix their work in an evidential context of uncertainty', often emphasizing that some of their conclusions are correct under some circumstances, or providing several explanations for a conclusion.

While the fundamental characteristics of the generic rhetorical structure are generally believed to be basically the same across languages and determined, to a large extent, by the international conventions of academic communication, some rhetorical strategies are found to be culture-specific (Peterlin, 2005, p. 308). However, due to the scarcity of cross-linguistic research on strategic hedges, cross-linguistic variation of hedging related to the rhetorical structure still has to be proved, and this study attempts to provide some evidence to support this assumption.

\section{Research Taxonomy}

This study aims at exploring frequency of occurrence and the main tendencies in using strategic markers of hedging in the Methods, Results, Discussion (and Conclusion) sections of research articles (RAs) from a cross-linguistic perspective. To this end, Koutsantoni's (2006) categorization of strategic hedges was adopted as a foundation for the research taxonomy. However, in this paper Kousantoni's classification is modified by extending the 'agreement with other research' subgroup by including, alongside with strategic hedges used to confirm the results by attributing claims to other researchers, strategic hedges aimed at justifying the choice of research methodology, substantiating the research implications, and explanations of the results or admitting to a lack oknowledge. The reason for including the above-mentioned types of agreement with other research into strategic hedges lies in the fact that, like other types of strategic hedges, they shift the responsibility for credibility of statements to other authors, which implies the author's hesitation about their validity and the resulting need for their reinforcement.

In contrast to Hyland's classification and following Koutsantoni (2006), in this paper the limitations of data or experimental conditions are included in the limitations of method. The reason for this is the fact that researchers often mention a combination of these limitations, making their isolation for measurement purposes difficult or impossible (for example, unavailability of data is frequently used to explain insufficient sample size, or deficiencies of the database are mentioned to account for the use of specific research variables).

\section{Corpus and Procedure}

Two corpora were used in this research: a corpus 
of Methods, Results and Discussion (and Conclusion) sections of 10 English-language research articles, and a corpus comprising the respective sections of 10 Russian-language articles in the field of management and marketing published dating from 2000 to 2014. The articles for the English corpus were randomly selected from several international journals with the impact factor for 2014/2015 not lower than 3: Journal of Management, Strategic Management Journal, Journal of International Management, Journal of Operations Management, Journal of Marketing, Research Policy. It is believed that, as all the articles have been accepted by English-speaking editorial boards, they substantially conform to the discourse or rhetorical conventions of the international English-speaking academic community. The Russian-language corpus comprised the respective sections of RAs published in three topranking Russian journals in this domain of science: Vestnik Sankt-Peterburgskogo Universiteta. Series 8. Management, Rossijskij Zhurnal Menedzhmenta, Economicheskyi Zhurnal Vysshey Shkoly Economiki. The limited number of Russian-language journals is explained by the fact that only these journals were found to contain articles that are comparable in length to the English-language ones, and follow the IMRD or IMRDC rhetorical structure accepted in many international journals on management and marketing. Introduction sections were excluded from the analysis for the following reason: due to the limited number of quality Russian journals in this domain and a disparity between international and Russian rhetorical / structural standards for RAs, selecting a sufficient number of articles which strictly followed the format mentioned seemed problematic. Many articles in Russian followed this structure in the concluding sections but failed to do so in the introductory sections (for example, contained a 'Literature review section'), thus impeding comparison between the two corpora.

This research employed a combination of quantitative and qualitative approaches in data collection and processing. The corpora were searched for strategic hedges manually as there is no software capable of identifying pragmatic or rhetorical functions of language units. All cases detected were then analyzed by two independent researchers. The quantitative approach in the form of simple frequency counts and percentages was used to get comparable data and to find frequencies. Following Koutsantoni (2006), the qualitative approach employed analysis of the detected items in their context by the two researchers trying to identify their pragmatic usage through text analysis. The number of hedges found in the English and Russian corpora were recorded, the hedges were classified according to the predetermined categories, and their proportions per category were counted manually and tabulated for both languages. Then, the detected strategic hedges were analyzed in terms of cross-linguistic differences in their frequency and usage.

\section{Results and Discussion}

The research aimed at detecting cross-linguistic variation in strategic hedging in English and Russian RAs on management and marketing indicated the same types of hedges for both corpora. Both the English (1) and Russian writers (2) admitted to limitations of method by mentioning unavailability of data, too small samples, restrictive conditions of research, imperfections in the research method or model:

(1) Like all research, ours has limitations that open up opportunities for future work.... Finally, since our study uses experiential simulation with fieldwork, future research could re-examine our predictions in an (albeit less controlled) industry setting (Chen, Katila, McDonald, \& Eisenhardt, 2010, p. 1544).

(2) Conducting longitudinal research on the discussed problems for separate industries is complicated by a lack of the information required (Nikulin \& Shatalov, 2012, p. 43).

In many cases, both the English and Russian authors attempted to provide a ground for choosing the imperfect data, methods or model through counterbalancing their drawbacks with advantages or giving reasons for their choice with the view of achieving research goals.

Both the English (3) and Russian (4) scientists often admitted to restrictions on the research scope, thus protecting themselves from a negative criticism of incompleteness of the study.

(3) ...the research took a 'bottom up' look at two real projects, but did not systematically research the broader company processes or functions ... (Hobday, 2000, p. 880).

(4) This paper does not touch upon the ways how this jointly created value is distributed among the chain members (Tret'jak \& Sloev, 2012, p. 37).

In both corpora, cases of admittance to limitations of knowledge were found $(5,6)$ :

(5) Whether or not these formal organizational solutions to the problems of organizational learning and career development work effectively remains to be seen (Hobday, 2000, p. 888).

(6) Differences in other aspects are less significant, which obscures the answer to the question if export to the markets of the former USSR has a learning effect (Golikova, Gonchar, \& Kuznecov, 2012, p. 18).

Both corpora also revealed multiple examples 
of agreement with other research to confirm the research method $(7,8)$ and results $(9,10)$, and a number of strategic hedges used to strengthen explanations and implications, as well as strategies aimed at indicating limitations of the study $(11,12)$.

(7) In line with previous studies (Das et al., 1998; Koh \& Venkatraman, 1991; Reuer, 2001), we used the following market model (Park, Mezias, \& Song, 2004, p. 15).

(8) In the present article an original model of strategic entrepreneurship is developed based on the scales proposed by Bierly and Daly (2007) and by Ireland and Webb (2007) (Shirokova \& Sokolova, 2011, p. 55).

(9) Consistent with the literature, our findings also indicate a direct, positive relationship between integration intensity and two financial measures (Rosenzweig, Roth, \& Dean, 2003, p. 450).

(10) These conclusions are in line with the outcomes of earlier research into the problem (Nikulin \& Shatalov, 2012, pp. 42-43).

(11) Our study uses cross-sectional data, which exclude tests for the effectiveness of detailed contract drafting and close partner selection over time (Wuyts \& Sou, 2005, p. 114).

(12) Verifying the approach in different industries may lead to modifying the relationship between customer acquisition and customer retention strategies depending on the branch of industry (Tret'jak \& Sloev, 2012, p. 48).

The quantitative results obtained for the Englishlanguage corpus are reported in Table 1.

The quantitative outcomes for the English corpus are comparable to Koutsantoni's (2006) research results with some exceptions. In this research, the most frequent strategies are found to be those pertaining to agreement with other research, while in Koutsantoni's research they are ranked fourth according to the order of frequency. This may be explained by the terminological differences: while Koutsantoni includes in this subgroup only those strategic hedges which prove similarity of the research outcomes to the results of other research, in the current paper a wider understanding is adopted (see above). The frequencies of agreement with other Koutsantoni's and the current research (12.5 and $10.2 \%$, respectively). The proportions of strategies acknowledging limited knowledge and limitations of the study are also similar (12.5 versus $10.2 \%$, and 10 versus $9 \%$, respectively). The differences between the results could be attributed to the cross-disciplinary research confirming the results are comparable in Koutsantoni's and the current research (12.5 and $10.2 \%$, respectively). The proportions of strategies acknowledging limited knowledge and limitations of
Table 1

Frequency of hedging strategies in the English corpus

\begin{tabular}{|c|c|c|c|c|}
\hline Category & & Number & $\%$ & Average per RA \\
\hline \multirow{5}{*}{ 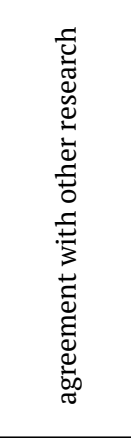 } & $\begin{array}{l}\text { confirming } \\
\text { the method }\end{array}$ & 91.0 & 37.3 & 9.1 \\
\hline & $\begin{array}{l}\text { confirming } \\
\text { the results }\end{array}$ & 25.0 & 10.2 & 2.5 \\
\hline & $\begin{array}{l}\text { strengthening } \\
\text { the research } \\
\text { implications }\end{array}$ & 7.0 & 2.9 & 0.7 \\
\hline & $\begin{array}{l}\text { strengthening } \\
\text { explanations }\end{array}$ & 7.0 & 2.9 & 0.7 \\
\hline & Subtotal & 130.0 & 53.3 & 13.0 \\
\hline \multirow{5}{*}{ 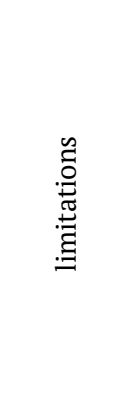 } & $\begin{array}{l}\text { limitations of } \\
\text { method }\end{array}$ & 47.0 & 19.3 & 4.7 \\
\hline & $\begin{array}{l}\text { limitations of } \\
\text { scope }\end{array}$ & 25.0 & 10.3 & 2.5 \\
\hline & $\begin{array}{l}\text { limitations of } \\
\text { knowledge }\end{array}$ & 20.0 & 10.2 & 2.0 \\
\hline & $\begin{array}{l}\text { limitations } \\
\text { of the study } \\
\text { (testability) }\end{array}$ & 22.0 & 9.0 & 2.2 \\
\hline & Subtotal & 114.0 & 46.7 & 11.4 \\
\hline Total & & 244.0 & 100.0 & 24.4 \\
\hline
\end{tabular}

the study are also similar (12.5 versus $10.2 \%$, and 10 versus $9 \%$, respectively). The differences between the results could be attributed to the cross-disciplinary variation of hedging reported by many researchers of academic discourse (Varttala, 2001; Vold, 2006) or the individual style of the authors. The most significant difference between Koutsantoni's results and this research is detected in the use of limitations of scope ( 25 versus $10.3 \%$ ). One explanation may also be the fact that the articles chosen for Koutsantoni's and this research represent different domains of science (engineering and management, respectively). Another explanation could lie in the fact that Introduction sections where limitations of scope seem to be among the most frequently used strategic hedges were excluded from this research due to the reason mentioned in the Corpus and procedure section of this article.

The results for the Russian corpus are presented in Table 2. As no similar studies have been found, the data cannot be compared to any previous research results.

As is evident from comparing the results presented in Table 1 and Table 2, the most frequently occurring strategies in both the English and Russian corpora are those which the authors used to confirm their statements by referring to other research. These strategies account for 53.3 and $54.7 \%$, respectively, so their proportions in the total number of strategic 
Table 2

Frequency of hedging strategies in the Russian corpus

\begin{tabular}{|c|c|c|c|c|}
\hline Category & & Number & $\%$ & Average per RA \\
\hline \multirow{5}{*}{ 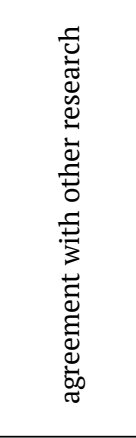 } & $\begin{array}{l}\text { confirming the } \\
\text { method }\end{array}$ & 45.0 & 32.8 & 4.5 \\
\hline & $\begin{array}{l}\text { confirming the } \\
\text { results }\end{array}$ & 25.0 & 18.3 & 2.5 \\
\hline & $\begin{array}{l}\text { strengthening } \\
\text { the research } \\
\text { implications }\end{array}$ & 1.0 & 0.7 & 0.1 \\
\hline & $\begin{array}{l}\text { strengthening } \\
\text { explanations }\end{array}$ & 4.0 & 2.9 & 0.4 \\
\hline & Subtotal & 75.0 & 54.7 & 7.5 \\
\hline \multirow{5}{*}{ 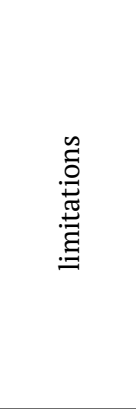 } & $\begin{array}{l}\text { limitations of } \\
\text { method }\end{array}$ & 24.0 & 17.5 & 2.4 \\
\hline & $\begin{array}{l}\text { limitations of } \\
\text { scope }\end{array}$ & 9.0 & 6.6 & 0.9 \\
\hline & $\begin{array}{l}\text { limitations of } \\
\text { knowledge }\end{array}$ & 20.0 & 14.6 & 2.0 \\
\hline & $\begin{array}{l}\text { limitations } \\
\text { of the study } \\
\text { (testability) }\end{array}$ & 9.0 & 6.6 & 0.9 \\
\hline & Subtotal & 62.0 & 45.3 & 6.2 \\
\hline Total & & 137.0 & 100.0 & 13.7 \\
\hline
\end{tabular}

hedges are similar for the English and Russian articles. The least frequently occurring strategies in both languages are those relating to strengthening the research implications and strengthening explanations (2.9 versus $0.7 \%$, and 2.9 and 2.9 , respectively). However, there are some differences in the percentages of strategic markers between the English and Russian corpora. The percentages of confirming the method and strengthening the research implications are higher in English than in Russian (37.3 versus 32.8, and 2.9 versus $0.7 \%$, respectively), while confirming the results ratio is significantly lower in English than in Russian (10.2 and $18.3 \%$, respectively). Percentages for limitations of method do not differ much given the fact that they are relatively high both in English and Russian; however, the corpora differ more or less significantly in the percentages of the strategies related to the limitations of scope (10.3 and 6.6\%, respectively), limitations of knowledge (10.2 and $14.6 \%$,) and limitations of the study (9 and 6.6\%, respectively). Surprisingly, the differences revealed in the percentages of different types of strategic hedges between the two corpora were not as considerable as it had been expected, which could probably be explained by the fact that the Russian journals selected for this research rank among the leading in the field and, therefore, try to follow the international standards.

However, Figure 1 and Figure 2 show that the most striking difference between the two corpora is the total number of strategic hedges in both categories (hedges related to agreement with other research and hedges indicating limitations).

In the English corpus 244 strategic hedges were detected as compared to 137 in the Russian one (1.8 times more), among them 130 and 75, respectively, express agreement with other research, and 114 and 62, respectively, indicate limitations. This is not surprising given the well-known higher density of hedges in English as compared to Russian. Due to different standards of international and Russian journals in the field, the sizes of the English and Russian corpora were not equal $(32,4640$ versus 25,350 words), which seems to make calculation of the exact ratio unfeasible. However, given the accepted fact that the number of hedges used in a research paper depends on multiple factors (the scientific domain, genre, part of the paper, individual style and other factors), the size of the article being only one of them, a significantly lower frequency of strategic hedges in the Russian corpus is evident.

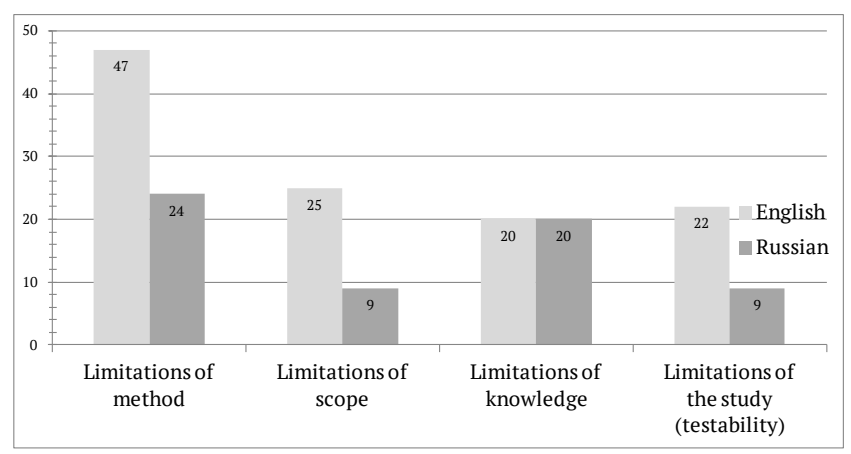

Figure 1. Overall number of strategic hedges using agreement with other research in the English and Russian corpora.

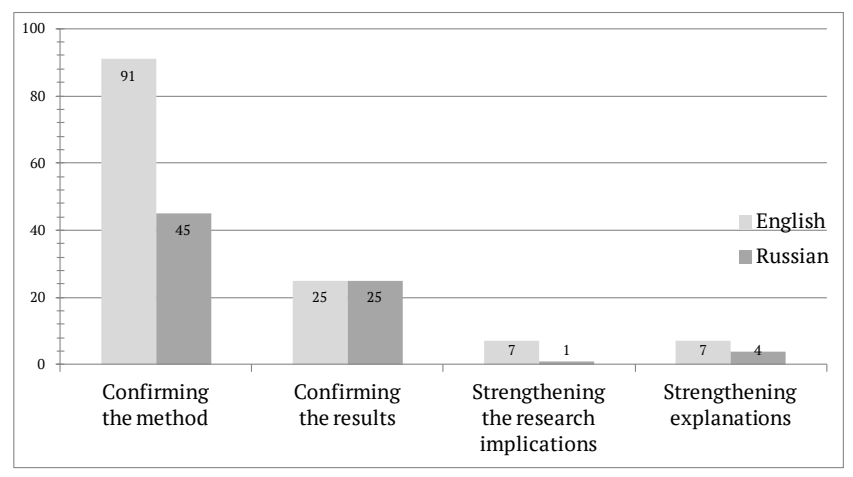

Figure 2. Overall number of strategic hedges expressing limitations in the English and Russian corpora.

Besides quantitative differences, the analysis revealed some qualitative dissimilarities between the English and Russian corpora. Among the most frequent differences the following ones could be mentioned: first, in expressing agreement with other research to confirm their statements the Russian scientists 
tended to use more references to general opinion (14) than English authors, while the latter preferred to cite specific authors (13) and used general opinion to confirm their statements only occasionally:

(13). These limitations relate primarily to restrictions in the simulation (for example, inability to make acquisitions (Puranam, Singh, \& Zollo, 2006)) (Chen et al., 2010, p. 1543).

(14) This tendency is one of the widely known features of regression analysis (Murav'ev, Berezinec, \& Il'ina, 2012, p. 14).

Another frequent difference between the corpora is in limitations of knowledge: while the English authors often gave two explanations for ambiguous definitions, results or phenomena (15), the Russian writers commonly provided one explanation, though in many cases a hedged one (16):

(15) These findings may indicate that e-commerce value creation potential is greater than traditional industries due to information exchange benefits, high reach and richness of information, and network effects. Alternatively, it could indicate that investors' speculation may be greater in this new and fast growing sector (Park et al., 2004, pp. 20, 22).

(16) This fact can be seen as an evidence of the influence the local labor market conditions exert on companies' policies in employee remuneration (Murav'ev et al., 2012, p. 22).

One more discrepancy is that Russian authors often used implicit or generalized ways of admitting to limitations (18), while English writers commonly used explicit and detailed ways of acknowledging these deficiencies (17). These tendencies are particularly apparent in the concluding sections of the articles where limitations are linked up with recommendations for further research:

(17) Third, since our additional analyses offer only a glimpse of performance threshold effects, more detailed analyses could examine these effects further (Chen et al., 2010, p. 1544).

(18) This article is only the first step on the way to understanding relations between shareholders, managers and employees of present-day Russian companies (Murav'ev et al., 2012, p. 29).

In these sections, many Russian writers completely omitted explicit limitations, substituting them for generalized acknowledgement of some imperfections in the study (or restating the focus of the study instead of mentioning limitations) and recommendations for further research (19):

(19) The research focus was on the customer flow model and the possibility to use its dynamics and structure in evaluating the results of value chain functioning. Further research could specify the contributions of each chain member, as well as describe profit distribution among the interaction participants (Tret'jak \& Sloev, 2012, p. 48).

Unfortunately, since no similar comparative research has been found, the reported qualitative differences could not be compared to other researchers' results.

A possible explanation for the reported qualitative and quantitative dissimilarity in using strategic hedges might be provided from the cross-cultural perspective. Though little research has been done into the cultural specificity of Russian academic discourse, it is accepted that cross-linguistic differences are rooted in incomplete convergence of national language pictures of the world while the latter is based on differences in national 'conceptual (cognitive) pictures of the world' and national mentalities. As the discourse features of academic writing are found to be culture specific (Hyland, 1995), this enables a surmise that the reported differences in strategic hedging including qualitative discrepancy and considerably higher frequencies of strategic hedges in English-medium as compared to Russian-medium academic discourse could be accounted for by specific differences in the national pictures of the world. However, determining these differences merits rigorous cross-cultural and cross-disciplinary analysis and is beyond the scope of this research.

\section{Conclusion}

Despite the accepted importance of hedging for academic writing and, consequently, for L2 ESP/EAP teaching and learning, as well as a large amount of research into lexical and syntactic hedging devices, strategic markers of hedging (Hyland, 2004a) have received little attention, particularly from crosslinguistic perspective. By focusing on comparing the types of strategic hedges, their frequencies and general tendencies for their use in English-language and Russian-language RAs on management and marketing, this study has sought to describe some most vivid differences between the two languages in this domain. The research revealed that the same types of strategic hedges are used by scientists writing in English and Russian: strategic hedges expressing agreement with other research to confirm or strengthen the method, results, their explanations or research implications, and strategic hedges admitting to limitations in the research method, scope, knowledge and the study (testability). However, the overall frequency of strategic hedges is significantly higher in the English RAs, and there are several important differences between the 
percentages of some specific types of strategic hedges between the languages. The qualitative differences detected comprise the Russian authors' aptitude for more frequent use of references to general opinion as compared to English authors, using one explanation for unclear results or phenomenon when admitting to a lack of knowledge, and preference for implicit over overt ways of acknowledging research limitations.

The current research has several implications. First, it could intensify linguists' interest in strategic hedges and their cross-linguistic variation in academic discourse. Second, as hedging is acknowledged to be a clear source of cultural difference, this study is expected to deepen understanding of strategic hedging importance among ESP/EAP researchers and teachers, as well as to inspire them to create ESP/EAP courses which could take into account cross-linguistic variation of this type of hedging with the view of helping L2 learners avoid cross-cultural pragmatic failures stemming from their unawareness of the differences described.

There are several limitations of the research to be acknowledged. First, the results were drawn from comparatively small corpora, and therefore, cannot be claimed to be either precise or conclusive. The size of the corpora as well as the research methodology also accounts for the mainly descriptive character of the study. However, the research did not aim at providing a detailed quantitative analysis of frequencies of strategic hedges and their specific types in Englishand Russian-medium articles in the domain; rather, its purpose was to offer a preliminary characterization of the most striking differences in their usage between the languages in this field. Further research could employ quantitative methods on larger corpora to test the results and to provide detailed quantitative research into frequencies of strategic hedging types in each of the languages for this or other domains. Frequencies of different types of strategic hedges and cross-linguistic differences of their usage could also be determined for rhetorical parts of RAs. Finally, by relying on cross-cultural research, future analysis could provide insights into the nature of crosslinguistic variation of strategic hedges.

\section{References}

Brown, P., \& Levinson, S. (1987). Politeness. Some universals in language usage. Cambridge, UK: Cambridge University Press.

Chen, E., Katila, R., McDonald, R., \& Eisenhardt, K. (2010). Life in the fast lane: Origins of competitive interaction in new vs. established markets. Strategic Management Journal, 31, 1527-1547.
Fløttum, K., Dahl, T., \& Kinn, T. (2006). Academic voices: Across languages and disciplines. Amsterdam, Netherlands: J. Benjamins Pub. Co.

Fraser, B. (2010). Pragmatic competence: The case of hedging. In G. Kaltenbock, W. Mihatsch \& S. Schneider (Eds.), New approaches to hedging (pp. 15-34). Bingley, UK: Emerald Group Publishers Limited.

Gillaerts, P., \& van de Velde, F. (2010). Interactional metadiscourse in research article abstracts. Journal of English for Academic Purposes, 9, 128-139.

Golikova, V. V., Gonchar K. R., \& Kuznecov, B. V. (2012). Vlijanie jeksportnoj dejatel'nosti na tehnologicheskie i upravlencheskie innovacii rossijskih firm [Impact of export activities on Russian companies' innovations in technology and management]. Rossijskij Zhurnal Menedzhmenta, 1(10), 3-28.

Hinkel, E. (2005). Hedging, inflating, and persuading in L2 academic writing. Applied Language Learning, $14,29-54$.

Hobday, M. (2000). The project-based organisation: An ideal form for managing complex products and systems? Research Policy, 29, 871-893.

Hyland, K. (2004a). Hedging in scientific research articles. Amsterdam, Netherlands: J. Benjamins Pub. Co.

Hyland, K. (2004b). Disciplinary interactions: Metadiscourse in L2 postgraduate writing. Journal of Second Language Writing, 13, 133-151.

Hyland, K., \& Tse, P. (2004). Metadiscourse in academic writing: A reappraisal. Applied Linguistics, 25, 156177.

Koutsantoni, D. (2006). Rhetorical strategies in engineering research articles and research theses: Advanced academic literacy and relations of power. Journal of English for Academic Purposes, 1(5), 1936.

Laane, M.-A. (2010, January). Strategies of hedging in science writing. In International Symposium 'Topical Problems in the Field of Electrical and Power Engineering'. Parnu, Estonia, Retrieved from http:// egdk.ttu.ee/files/parnu2010/Parnu2010_003-007. pdf

Lakoff, G. (1972). Hedges: A study in meaning criteria and the logic of fuzzy concepts. In P. Peranteau, J. Levi \& G. Phares (Eds.), Papers from the Eighth Regional Meeting of the Chicago Linguistic Society (pp. 183-228). Chicago, IL: University of Chicago Press.

Lewin, B. (2005). Hedging: An explanatory study of authors' and readers' identification of 'toning down' in scientific texts. Journal of English for Academic Purposes, 4, 163-178.

Murav'ev, A. A., Berezinec, I. V., \& Il'ina, Ju. B. (2012). Korporativnye konflikty i politika firm v oblasti zanjatosti i zarabotnoj platy [Corporate governance 
conflicts and employment and wage policies of companies]. Rossijskij Zhurnal Menedzhmenta, 2(10), 3-32.

Nikulin, E. D., \& Shatalov, A. I. (2012). Strategija rosta biznesa $\mathrm{s}$ ispol'zovaniem franchajzinga: Balans mezhdu chislom sobstvennyh predprijatij i chislom predprijatij-partnerov [Business growth strategies employing franchising: A balance between own companies and partners' companies number]. Vestnik Sankt-Peterburgskogo Universiteta, 3(8), 2547.

Park, N., Mezias, J., \& Song, J. (2004). A resource-based view of strategic alliances and firm value in the electronic marketplace. Journal of Management, 30(1), 7-27.

Peterlin, A. P. (2005). Text-organizing metatext in research articles: An English-Slovene contrastive analysis. English for Specific Purposes, 24, 307-319.

Rosenzweig, E., Roth, A., \& Dean, J. (2003). The influence of an integration strategy on competitive capabilities and business performance: An exploratory study of consumer products manufacturers. Journal of Operations Management, $21,437-456$.

Salager-Meyer, F., Ariza, M. A. A., \& Zambrano, N. (2003). The scimitar, the dagger and the glove: Intercultural differences in the rhetoric of criticism in Spanish, French, and English medical discourse. English for Specific Purposes, 22(3), 223-247.

Shirokova, G. V., \& Sokolova, L. S. (2011). Strategicheskoe predprinimatel'stvo: Podhody $\mathrm{k}$ issledovaniju i rossijskaja praktika [Strategic entrepreneurship: Research approaches and Russian practices]. Vestnik Sankt-Peterburgskogo Universiteta, 3(8), 32-59.

Swales, J. M. (1990). Genre analysis. Cambridge, UK: Cambridge University Press.

Swales, J., \& Feak, C. (2000). English in today's research world: A writing guide. Ann Arbor, MI: University of Michigan Press.

Tret'jak, O. A., \& Sloev, I. A. (2012). Ocenka marketingovoj dejatel'nosti po sostojaniju klientskogo potoka [Assessing marketing activity by customer flow]. Rossijskij Zhurnal Menedzhmenta, 1(10), 29-50.

Varttala, T. (2001). Hedging in scientifically oriented discourse: Exploring variation according to discipline and intended audience (Unpublished doctoral dissertation). University of Tampere, Tampere, Finland.

Vassileva, I. (2001). Commitment and detachment in English and Bulgarian academic writing. English for Specific Purposes, 20(1), 83-102.

Vold, E. T. (2006). Epistemic modality markers in research articles: A cross-linguistic and crossdisciplinary study. International Journal of Applied Linguistics, 1(16), 61-87.

Wuyts, S., \& Sou, I. (2005). The formation of buyersupplier relationships: Detailed contract drafting and close partner selection. Journal of Marketing, 4(69), 103-117. 